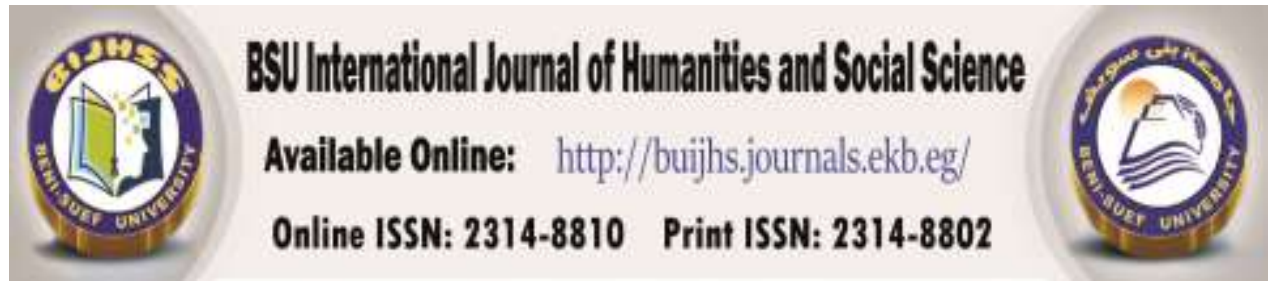

\title{
The Awareness of the Faculty Members And Their Assistantsin Beni-Suef University towards \\ The Aplications of Web 2.0
}

\section{Associate Prof Dr: Mohammad, Maha Ahmad Ibrahim 1}

\section{E-MaiL: Mahaahmd 2003@art.bsu.edu.eg}

ABSTRACT

Keywords:

Web 2.0, Aplications research. This study aims at measuring the attitudes of of Web 2.0 opportunity to learn about the latest developments and technologies in the area of the internet in general, and the world of the Web in particular, to be able to make use of them in carrying out his academic work and
A University professor must be allowed an the Faculty members toward the techniques of Web 2.0. The researcher has chosen the Faculty members and the teaching assistants at Beni-Suef University as examples.

The importance of the internet and its impact on modern life cannot be denied. It has been able to change the pattern of modern life, to innovate different concepts and patterns of requirements, which have transformed the world into a small village thanks to the technology of communication, which made the Internet a window through which researchers and scientists acquire various kinds of knowledge and cultures

this study tries to answer the following queries: To what extent the Faculty members of Beni-Suef University and their assistants use the Internet?, What 
are their skills in using the internet, and to what extent they benefit from the service of browsing? ,To what extent are the Faculty members of Beni-Suef University and their assistants aware of the importance Web 2.0?,The ways through which the Faculty members of Beni-Suef University and their assistants acquire the available information about the Web 2.0. ,How much knowledge do the Faculty members of Beni-Suef University and their assistants have about Web 2.0? ,To what extent the Faculty members of Beni-Suef University and their assistants use the services and sites available through the techniques of Web 2.0?, What are the opinions of the Faculty members of Beni-Suef University and their assistants on the services and available sites through the techniques of Web 2.0?

This study attempts to measure the extent of the Faculty members of Beni-Suef University and their assistants' use of the applications of Web 2.0, the time limit of this study is the academic year 2011/2012 $\mathrm{AD}$, when the researcher collected the data needed to conduct the study through the distribution of the questionnaire on the sample during this period.

\section{Introduction}

The scientific and technical rise which the world is living now is accompanied by a parallel interest in keeping pace with these rapid developments, from the part of academic, educational institutions, researchers, with the aim of benefitting from these developments in all fields. The attitudes of these institutions and individuals towards these developments were uneven, as they ranged from taking advantage of these developments ending in radical changes, to taking active steps, while trying to make sure of the extent of their impact on analogues, and there is a class that stood idly by, and refrained from keeping up with the progress, and taking advantage of the new developments for reasons that may be economical or epistemological. 
The Internet web with its services and various applications represent an important tributary stream of getting information, and inventing various services. There has been a strategic development in the past few years on the nature of services and applications used, and led to the emergence of the socalled interactive Web, which is called the Web 2.0 in 2005.

It can be argued that the internet is a doubl-edged sword, especially with these great developments of the Web; it is a weapon of strength and construction, at the same time a weapon of weakness and demolition. Therefore, we would like to be aware of the perils of the future when dealing with this technology, to determine our way, and put our hands on the best way that should be taken, and get the utmost benefit from it in our real life.

\section{Importance of the Study:}

The importance of the internet and its impact on modern life cannot be denied. It has been able to change the pattern of modern life, to innovate different concepts and patterns of requirements, which have transformed the world into a small village thanks to the technology of communication, which made the Internet a window through which researchers and scientists acquire various kinds of knowledge and cultures.

Scientific research is considered a measure of the progresss of nations and peoples, to gauge their development in all walks of life. Therefore, the University professor is the basis on which scientific research is carried out, that contribute to the development of scientific research and progress.

A University professor must be allowed an opportunity to learn about the latest developments and technologies in the area of the internet in general, and the world of the Web in particular, to be able to make use of them in carrying out his academic work and research. This study aims at measuring the attitudes of the Faculty members toward the techniques of Web 2.0. The researcher has chosen the Faculty members and the teaching assistants at Beni-Suef University as examples. 


\section{Objectives of the Study:}

Given the importace of the study, the researcher previously referred to, the researcher aims, through this study, at recognizing the actual fact of the Faculty members' use of the applications of Web 2.0, measuring their attitudes, and showing the extent of their knowledge and awareness of them.

In the light of all this, this study tries to answer the following queries:

1- To what extent the Faculty members of Beni-Suef University and their assistants use the Internet?

2- What are their skills in using the internet, and to what extent they benefit from the service of browsing?

3- To what extent are the Faculty members of Beni-Suef University and their assistants aware of the importance Web 2.0?

4- The ways through which the Faculty members of Beni-Suef University and their assistants acquire the available information about the Web 2.0.

5- How much knowledge do the Faculty members of Beni-Suef University and their assistants have about Web 2.0?

6 - To what extent the Faculty members of Beni-Suef University and their assistants use the services and sites available through the techniques of Web 2.0

7- What are the opinions of the Faculty members of Beni-Suef University and their assistants on the services and available sites through the techniques of Web 2.0? 


\section{Field of the Study and its limits:}

This study attempts to measure the extent of the Faculty members of Beni-Suef University and their assistants' use of the applications of Web 2.0, the time limit of this study is the academic year 2011/2012 AD, when the researcher collected the data needed to conduct the study through the distribution of the questionnaire on the sample during this period.

\section{Methodology of the Study and Data Collection Tools:}

Due to the nature of this study the researcher follows the field survey method, which aims at reporting the characteristics of a particular phenonmenon depending on the collection of facts, analysis and interpretation, to use their implications in carrying out the objectives of the study being the nearest appropriate methodology to identity the impact of some of the variables on the extent of the use of the Faculty members and their assistants of the applications the Web 2.0

The researcher makes use of the questionnaire as a tool of data collection: the purpose is to reflect the views of the Faculty members and their assistants on the applications of Web 2.0, it has been judged by experts and professors of library and information to endorse their validity.

\section{Review of Literature:}

There Are Several Studies Which dealt with Web 2.0:

\section{$\checkmark$ Web 2.0: Conceptual foundations and marketing issues $\left({ }^{1}\right)$}

This paper identifies the technological and commercial foundations of the new category of online applications commonly described as Web 2.0 or Social Media. It examines the relevance of Web 2.0 for Marketing Strategy and for Direct Marketing in particular.

The issue is not a clear-cut one: while several observers saw in Web 2.0 a new stage in the evolution of the internet, others simply rejected it as a new High-Tech hype while there is still no generally accepted definition and demarcation of the term. Paradoxically, even without an accepted definition 
and despite lack of extensive research, the corporate world seems to embrace the Web 2.0 concept: high-profile mergers and acquisitions have already taken place or are under way while corporations are rushing to integrate various forms of social media into their marketing planning. The experience so far, based to a large degree on anecdotal evidence, is that Web 2.0 has a substantial effect on consumer behaviour and has contributed to an unprecedented customer empowerment. The consequences are far reaching, affecting not only the area of technology development but also the domains of business strategy and marketing. From the academic but also the practical point of view, attention must be placed on the demarcation and evaluation of the new technologies and trends so that the real value of Web 2.0 as a component of the modern marketing can be determined.

\section{$\checkmark$ The emerging Web 2.0 social software: an enabling suite of sociable technologies in health and health care education(2)}

Web 2.0 sociable technologies and social software are presented as enablers in health and health care, for organizations, clinicians, patients and laypersons. They include social networking services, collaborative filtering, social bookmarking, folksonomies, social search engines, file sharing and tagging, mashups, instant messaging, and online multi-player games. The more popular Web 2.0 applications in education, namely wikis, blogs and podcasts, are but the tip of the social software iceberg. Web 2.0 technologies represent a quite revolutionary way of managing and repurposing/remixing online information and knowledge repositories, including clinical and research information, in comparison with the traditional Web 1.0 model. The paper also offers a glimpse of future software, touching on Web 3.0 (the Semantic Web) and how it could be combined with Web 2.0 to produce the ultimate architecture of participation.

Although the tools presented in this review look very promising and potentially fit for purpose in many health care applications and scenarios, careful thinking, testing and evaluation research are still needed in order to establish 'best practice models' for leveraging these emerging technologies 
to boost our teaching and learning productivity, foster stronger 'communities of practice', and support continuing medical education/professional development (CME/CPD) and patient education.

\section{$\checkmark$ Library 2.0 Theory: Web 2.0 and Its Implications for Libraries (3)}

This article posits a definition and theory for "Library 2.0". It suggests that recent thinking describing the changing Web as "Web 2.0" will have substantial implications for libraries, and recognizes that while these implications keep very close to the history and mission of libraries, they still necessitate a new paradigm for librarianship. The paper applies the theory and definition to the practice of librarianship, specifically addressing how Web 2.0 technologies such as synchronous messaging and streaming media, blogs, wikis, social networks, tagging, RSS feeds, and mashups might intimate changes in how libraries provide access to their collections and user support for that access.

\section{$\checkmark$ LANGUAGE LEARNING IN SECOND LIFE: American and Turkish Students' Experiences (4)}

There have been several attempts to integrate Web 2.0 technologies including podcasts, weblogs, wikis, and virtual 3D communities into language education thus far. Second Life, a virtual 3D community, might create unique opportunities for language learners specifically in the following ways: As a source of authentic interaction with target language speakers, a venue for language classes, and an autonomous study opportunity for learners. In this context, this study reports Second Life experiences of American students learning Turkish as a foreign language in the University of Florida, the USA and of Turkish students learning English as a foreign language at Gazi University, Turkey. The interviews demonstrated that both groups of students regarded Second Life as a contribution to authentic interaction with native language. Furthermore, the experiences indicated Second Life served as a good bridge for cultural competence and an inevitable tool to foster less threatened learning experiences despite challenges encountered on the way. 


\section{$\checkmark$ A RESTful technique for collaborative learning content}

\section{transclusion by Wiki-style mashups(5)}

In this paper we propose a simple pragmatic technique, called fladget, for enabling end-users to mashup multimedia content within Wiki pages of their community peers. Since the fladget considers Wiki as a content as well as mashup repository service, Wiki RESTful API is proposed. The fladget extends functionality of existing plugin mechanism, so it can use rich-client technology for interaction with distributed multimedia content, but in a pragmatic Wiki-like manner. The presented concept is illustrated by a hypothetical Linked Active Learning Community example demonstrating how the presented mechanism can be used at the community interaction level.

\section{$\checkmark$ Web 2.0 applications as alternative environments for informal learning - a critical review( 6 )}

Enthusiastic educational commentators are casting the internet in a new light through the emergence of so-called 'Web 2.0' technologies, which place learners at the centre of online activities and facilitate supposedly new forms of creation, collaboration, and consumption. Proponents anticipate a host of new pedagogical challenges posed by a 'Facebook generation' of 'wiki kids,' whilst schools and colleges are delivering courses in 'Second Life' rather than real-life environments. An impassioned minority of educationalists has even heralded a 'Web 2.0 transformation of learning' with "potentially groundbreaking implications for the field of education" . Yet such enthusiasm has been tempered by a more sceptical reaction throughout other sectors of the educational and technology communities. Mindful of these debates, this presentation will overview briefly the emerging research literature in the area of Web 2.0 enhanced learning (specifically the Facebook and Second Life applications) and focus on the following issues: 
- what evidence is there for informal learning taking place within Web 2.0 applications, and if so, in what ways? Can Web 2.0 applications be designed to facilitate informal learning?

- What potential benefits and risks do Web 2.0 applications pose for formal learningin educational institutions such as schools? Does Web 2.0 herald the increased individualization and personalization of informal online learning at the expense of learning in more formal offline settings?

\section{$\checkmark$ Mashing, burning, mixing and the destructive creativity of Web 2.0: applications for medical education}

This Study dealt examine the recent growth of social software (Web 2.0) and its initial impact on education, and offer a review of some of the recent research conducted in the evaluation of its pedagogical applications.highlight the propensity of students to be both creative and destructive in their use of social software, particularly with wikis, web logs (blogs) and other text based environments. Student activities within these social software environments can cause tension and conflict, and reactions vary, but outcomes have been generally positive. Some medical education examples are reviewed, providing the reader with worked examples of the use of social software in action in clinical education contexts(7)

\section{Sample of the Study:}

Since the primary objective of the study is to identify the use of the Faculty members and teaching assistants at Beni-Suef University of the applications of Web 2.0, the community of the study is - naturally composed of the members of the University Faculty and their assistants. The research sample is selected non-randomly, the Quatra purposes sample known as Quat(8), the Quatra purposes sample ensures the objectivity and impartiality of the study through their representation of specific portions of sub-categories that make up the community of the study. 


\section{Community of the Study:}

Since the main objective of the study is to be acquainted with the measurement of behaviors and trends of the Faculty members and teaching assistants at Beni-Suef University towards the applications of Web 2.0. The community of the study is - of course - composed of the members of the Faculty and teaching assistants in Beni-Seuf University. The University includes about (1725) members and assistants, and about (87) emeritus and non-emeitus professors, (**) the following table (1) where the Faculty members and assistants are demonstrated according to their job ranks:

Table (1)

Numbers of the Faculty and their Assistants in Beni- Suef University According to their Job Ranks

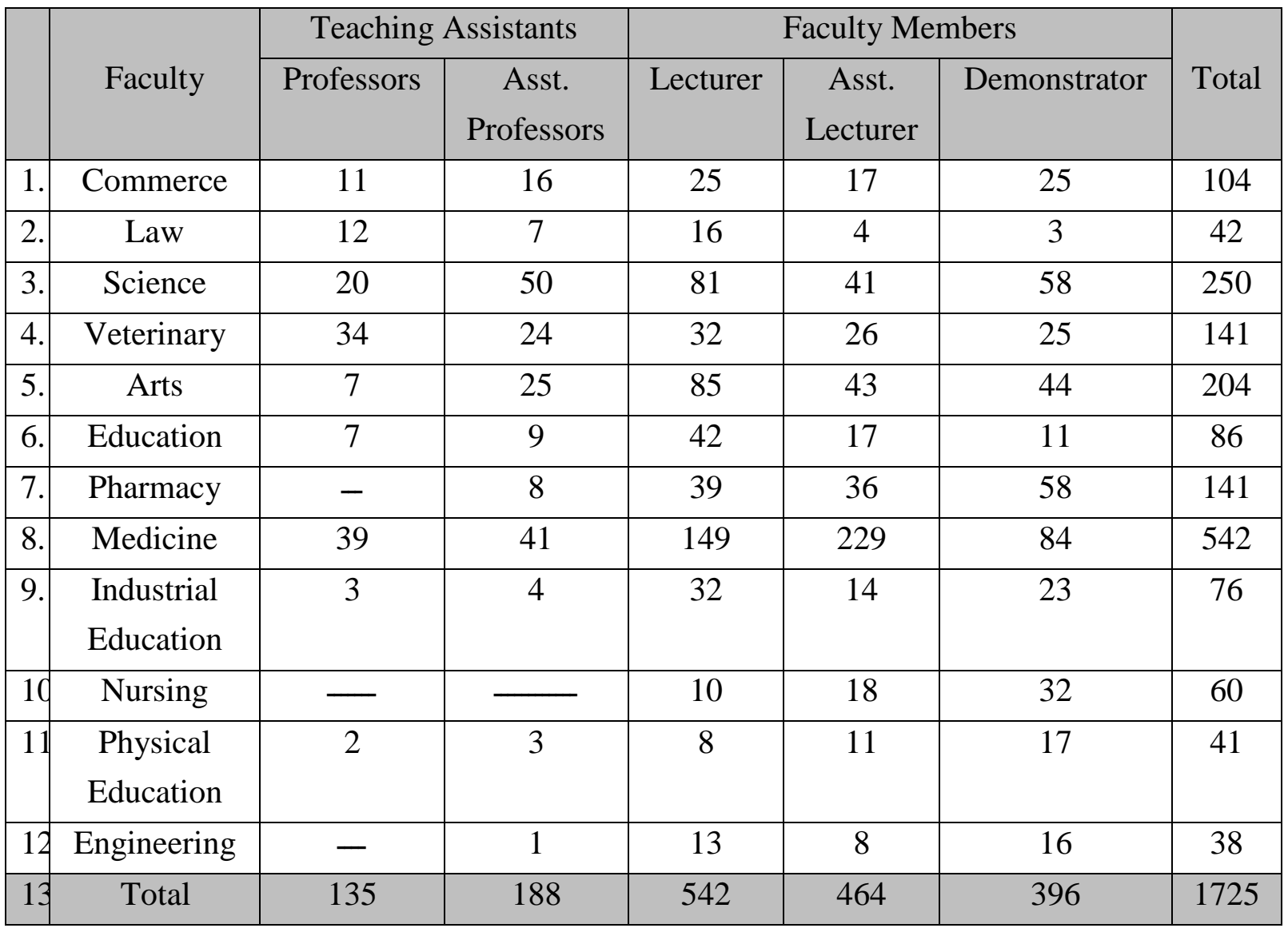


The following timetable (2) shows the numbers of the Faculty members: professors, assistant professors, and emeritus and non-emritus professors:

\section{Table (2)}

Numbers of the Faculty Members, of Professors, Assistant Professors, Emeritus and Non-emeritus Professors

\begin{tabular}{|l|l|c|c|c|}
\hline \multirow{2}{*}{ Serial } & \multirow{2}{*}{ Faculty } & \multicolumn{2}{c|}{ Emeritus } & \multirow{2}{*}{ Total } \\
\cline { 3 - 4 } & & emeritus & Non-emeritus & \\
\hline & Commerce & 13 & 2 & 15 \\
\hline & Law & 12 & 5 & 17 \\
\hline & Science & 12 & 2 & 14 \\
\hline & Veterinary & 6 & 2 & 8 \\
\hline & Arts & 17 & 4 & 21 \\
\hline & Education & 6 & - & 6 \\
\hline & Pharmacy & - & - & - \\
\hline & Medicine & 3 & - & 3 \\
\hline & Industrial Education & 3 & - & 3 \\
\hline & Nursing & - & - & - \\
\hline & Physical Education & - & - & - \\
\hline & Engineering & - & - & - \\
\hline & Total & 72 & 15 & - \\
\hline
\end{tabular}

\section{Sample of the Study:}

Due to the large size of the study, the researcher chose the sample of the study to be based on statistical Stratified Sampling, which uses the method of statistical stratified sample on the classification or division of the items of the community of the study into consistent categories, and on line with the purposes of the study. The researcher takes a simple, random or regular of each category, to get at last a group of samples and sub-samples of equal size proportions, and the degree of their presence in the community of the study. This means that the study depends on the stratified sample where relative samples are randomly chosen according to the same sample percentage of each layer, this will produce a range of smaller specimens, 
proportioned directly in size with their presence in the community of the origin.

On selecting the sample of the study, the researcher takes into account its being representative of the community of the study in terms of containing all the faculties of Beni-Suef University, theoretical and practical colleges, in addition to representing all academic degrees in each Faculty, from the degree of professor to the degree of demonstrator, where the sample is identified as being $20 \%$ of the total number of the items of the community of the study, with the addition of $1 \%$ for including the emeritus professors, in addition to the assistant professors on pension. The following table (3) shows the sample of the study:

Table (3)

Number of the Faculty Members and Assistants and the Number of Members Represented in the Sample

\begin{tabular}{|c|c|c|c|}
\hline Serial & Faculty & $\begin{array}{c}\text { The total } \\
\text { number } \\
\text { ofFaculty } \\
\text { members } \\
\text { andassistants }\end{array}$ & $\begin{array}{l}\text { Number of members } \\
\text { ofstaffrepresentedinthe } \\
\text { study sample }\end{array}$ \\
\hline 1. & Commerce & 104 & 20 \\
\hline 2. & $\overline{\text { Law }}$ & 42 & $\overline{88}$ \\
\hline 3. & Science & 250 & 50 \\
\hline 4. & Veterinary & 141 & 28 \\
\hline 5. & Arts & 204 & 40 \\
\hline 6. & Education & 86 & 17 \\
\hline 7. & Pharmacy & 141 & 28 \\
\hline 8. & Medicine & 542 & 108 \\
\hline 9. & Industrial Education & 76 & 15 \\
\hline 10. & Nursing & 60 & 12 \\
\hline 11. & Physical Education & 41 & 8 \\
\hline \multirow[t]{2}{*}{12.} & Engineering & 38 & 7 \\
\hline & Total & 1725 & 341 \\
\hline
\end{tabular}


In the above table it is clear that the study sample that will be applied represents 341 members, distributed over twelve colleges (the subject of the study), the questionnaire has been distributed during the academic year 2011/2012. The researcher found a low level of response to filling the questionnaire; as the number of filled out questionnaires reached 218, with 26 excluded for invalidity, the number of valid questionnaires - thus reached 192 applicable to the study sample, identified in advance. The researcher, then, unloaded data, conducted the statistical tests, and extracted averages, and percentages which she converted into tables of positive and negative significance useful in knowing the aspects of the research.

\section{Web 2.0 Definition:}

\section{Web 2.0}

This term appeared for the first time in a meeting held between the "O'Reilly Media" Foundation, and "Medialive International" foundation, where experts have tried, in this meeting, to find an access to the determined criteria through which web sites may be divided into sites of Web 1.0 (traditional), and sites of Web 2.0 (new generation of sites in that time).

Web 2.0 is a term that refers to a group of new techniques that lead to changing the conduct of the internet which redefined Web 2.0 as a group of websites and applications which possess the following characteristics:

\section{1- a high degree of interactivity with the user.}

This interactivity represents the feeling of the user on using one of the applications of Web 2.0, as if using one of the desktops, and the technology which contributed to raising the efficiency of applications of Web 2. 0, it is the technique called $A J A X$ which made them more interactive.

\section{2- Participation of the User in the content.}

In the past, the website was a read-only site; the content on the Web was edited by people belonging to companies, universities, and private or government institutions. The average user of the internet was not able to 
contribute to the published content. At present it has become easy for the user to add or modify, so as to enrich the content of the Web. The user became the essential element in the process of enriching the content of the Web, through the possibility of making the content. Applications such as blogs and wikis have contributed to make the Web a platform of read/write Web after it had been a platform for reading only.

冈 Users are allowed to use software depending on the browser/site only. Therefore, these users can possess their databases in addition to the ability to control them.

冈 Allowing users to add values to these (software-based browser).

冈 Allowing users to express themselves, their interests and cultures.

冈 Imitating the experience of desktop users operating by providing them with features and applications similar to their personal computer environments.

冈 Providing users with interactive systems through their participation in social interaction.

$凶$ Allowing users to modify the database by adding, changing or deleting information.

3- The possibility of describing the content: since the main part of the technology of Web2.0 is based on the existence of the content contributed by the user, either directly or indirectly, it was necessary to find a way to help the user to describe these contents to be counted, arranged, and prepared for reference, and re-employ in future use. $\left({ }^{9}\right)$

Ahmad Farag refers to the basic principles and qualities related to Web 2. 0

- Developing the methods and patterns of interactive communication via communication among Internet users, communication between sites and online portals, the connection between information networks, communication between sites and mobiles networks, communication between businesses and customers of "electronic commerce." 
The Web 2.0 includes all previous communicative systems.

- Treating users as participants in developing the applications, the main objective of the applications related to the social, electronic contents, blogs and virtual spaces in activating and developing the status of users and granting them priorities, and special status through validity of participation in the contents, and thus the priorities of users precede those of the programmers and companies alike.

Services are imporved with the increase in the number of users.

- Hypervelocity contact: Web 2.0 is characterized by the participation of users with multimedia files (pictures, sound, moving pictures, and text files) as it is in the Youtube, the work of this kind of files relies on ultra-fast contact called Broadband, more dependent on the contact based on the access to the internet via land lines.

- Providing control of information through flexible interfaces: Ajax Applications allow the user to control and arrange information on desire, and thus the Web becomes larger than a mere environment to review data, it can be viewed as being a place to interact with the user.

\section{Web 2.0}

Is the term given to describe a second generation of theWorld Wide Web that is focused on the ability for people to collaborate and share information online. Web 2.0 basically refers to the transition from static HTML Web pages to a more dynamic Web that is more organized and is based on serving Web applications to users. Other improved functionality of Web 2.0 includes open communication with an emphasis on Web-based communities of users, and more open sharing of information. Over time Web 2.0 has been used more as a marketing term than a computer-science-based term. Blogs, wikis, and Web servicesare all seen as components of Web 2.0. $\left({ }^{10}\right)$ 


\section{Web 2.0}

Is the network as platform, spanning all connected devices; Web 2.0 applications are those that make the most of the intrinsic advantages of that platform: delivering software as a continually-updated service that gets better the more people use it, consuming and remixing data from multiple sources, including individual users, while providing their own data and services in a form that allows remixing by others, creating network effects through an architecture of participation, and going beyond the page metaphor of Web 1.0 to deliver rich user experiences(11)

Web 2.0, the second phase in the Web's evolution, is attracting the attention of IT professionals, businesses, and Web users. Web 2.0 is also called the wisdom Web, people-centric Web, participative Web, and $\mathrm{read} / \mathrm{write}$ Web. Web 2.0 harnesses the Web in a more interactive and collaborative manner, emphasizing peers' social interaction and collective intelligence, and presents new opportunities for leveraging the Web and engaging its users more effectively. Within the last two to three years, Web 2.0, ignited by successful Web 2.0 based social applications such as MySpace, Flickr, and YouTube, has been forging new applications that were previously unimaginable. $\left({ }^{12}\right)$

\section{The Web As Platform(13)}

Like many important concepts, Web 2.0 doesn't have a hard boundary, but rather, a gravitational core. You can visualize Web 2.0as a set of principles and practices that tie together a veritable solar system of sites that demonstrate some or all of those principles, at a varying distance from that core. 


\section{Web 2.0 Meme Map}

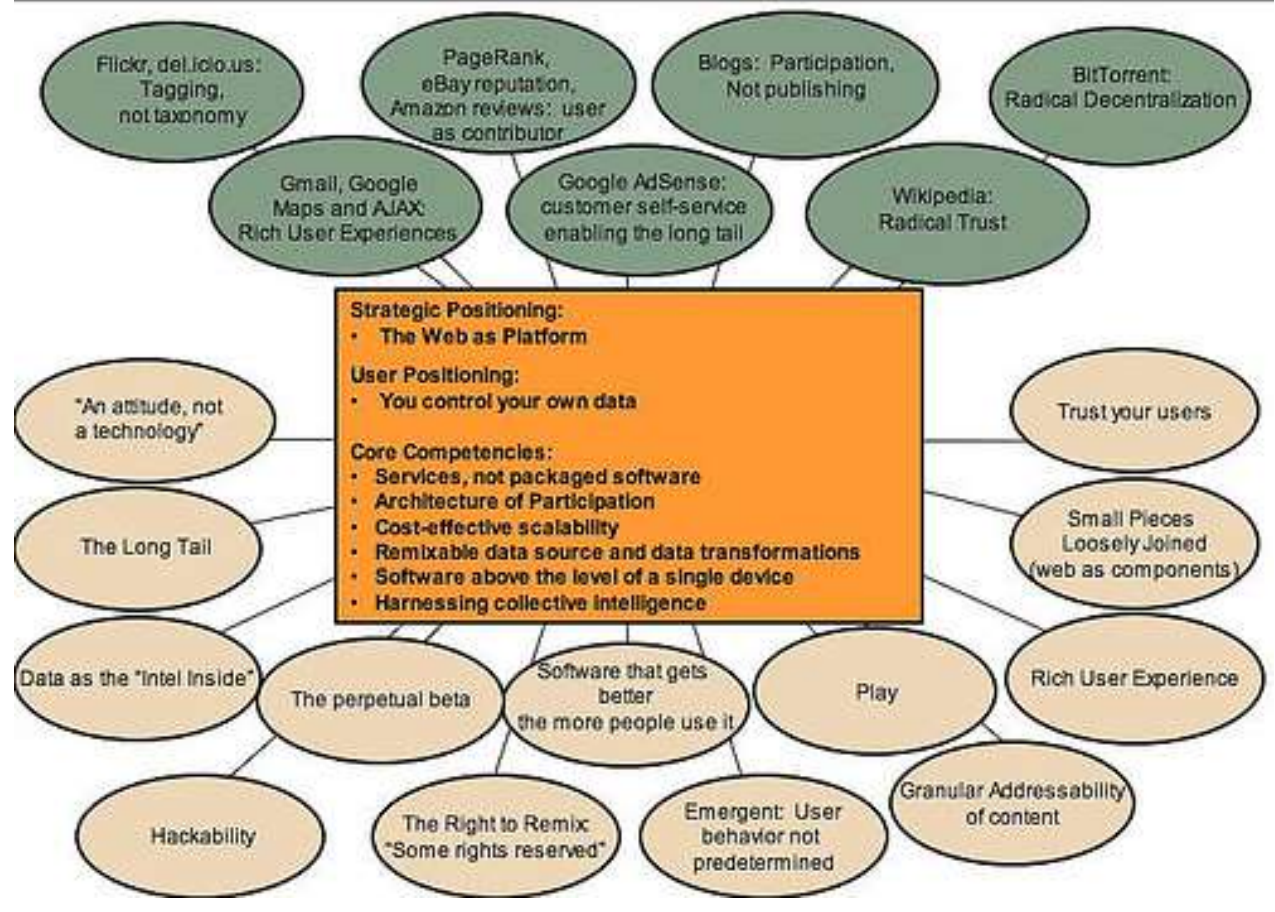

Figure 1 shows a "meme map" of Web 2.0 that was developed at a brainstorming session during FOO Camp, a conference at O'Reilly Media. It's very much a work in progress, but shows the many ideas that radiate out from the Web 2.0 core.

For example, at the first Web 2.0 conference, in October 2004, John Battelle and I listed a preliminary set of principles in our opening talk. The first of those principles was "The web as platform." Yet that was also a rallying cry of Web 1.0 darling Netscape, which went down in flames after a heated battle with Microsoft. What's more, two of our initial Web 1.0 exemplars, DoubleClick and Akamai, were both pioneers in treating the web as a platform. People don't often think of it as "web services", but in fact, ad serving was the first widely deployed web service, and the first widely deployed "mashup" (to use another term that has gained currency of late).

Every banner ad is served as a seamless cooperation between two websites, delivering an integrated page to a reader on yet another computer. Akamai also treats the network as the platform, and at a deeper level of the stack, building a transparent caching and content delivery network that eases bandwidth congestion. 
Nonetheless, these pioneers provided useful contrasts because later entrants have taken their solution to the same problem even further, understanding something deeper about the nature of the new platform. Both DoubleClick and Akamai were Web 2.0 pioneers, yet we can also see how it's possible to realize more of the possibilities by embracing additional Web 2.0 design patterns.

Let's drill down for a moment into each of these three cases, teasing out some of the essential elements of difference.

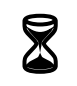

Before moving to identify the way the Faculty members and their assistants in Beni-Suef University use web applications of Web 2.0. The researcher would like to draw attention to the fact that Web 2.0 is not the end of the story, but the beginning, and that the future of Web 2.0 was followed by developments. It has been mentioned that Web 2.0 appeared in 2005, and followed in 2006 by a new generation of Web called Web 3.0 and is also called the semantic Web, soon another generation of Webs appeared called Web. 4.0 in the late 2008, to be followed by a third in the early 2009, also known as Symbiotic Web.

It is important to mention that the Faculty members and their assistants in Beni-Suef University should keep pace with the developments in Webs, and should not stop at a certain limit. This study is an attempt towards doing this. In addition, it attempts to recognize the reality, and prognosticate the future. 


\section{Analysis of Data:}

\section{First: General Data of the Community of the Study:}

The researcher wanted to review the general raw data of the community of the study in an abstract mode just to give personal background, and a clear image of the whole community of the study (members of the teaching staff, and assistants), the following table (4) demonstrates the primary data:

Table (4)

Personality Traits of the Study Sample

\begin{tabular}{|c|c|c|c|}
\hline$\%$ & $\begin{array}{l}\text { Numb } \\
\text { er }\end{array}$ & & \\
\hline 54.1 & 104 & Male & \multirow{2}{*}{ gender } \\
\hline 45.9 & 88 & Female & \\
\hline 100 & 192 & \multicolumn{2}{|c|}{ Total } \\
\hline 22.4 & 43 & Less than 30 & \multirow{5}{*}{ Age } \\
\hline 36.00 & 69 & From $30-39$ & \\
\hline 29.2 & 56 & From $40-49$ & \\
\hline$\overline{9.8}$ & 19 & From $50-59$ & \\
\hline 2.6 & 5 & From 60 - & \\
\hline 100 & 192 & Total & \\
\hline 2.1 & 4 & Professor & \multirow{5}{*}{ Degree } \\
\hline 20.3 & 39 & Assistant Professor & \\
\hline 33.3 & 64 & Lecturer & \\
\hline 19.8 & 38 & Assistant lecturer & \\
\hline 24.5 & 47 & Demonstrator & \\
\hline 100 & 192 & Total & \\
\hline
\end{tabular}

Table number (1) shows the general personality features of the community of the study, where the results showed that $54.1 \%$ of the participants were male, while the percentage of female participants amounts 
to $45.9 \%$, which is less than male participants. As for the ages of the participants, they run as follows: from 30 - 39 is higher than $36.0 \%$, followed by a percentage of whose ages range from 40 - 49, with a percentage of $29.2 \%$, then those whose ages are less than 30 years with a percentage of $22.4 \%$, with a clear difference from the percentage of whose ages are 50 with a percentage of $59 \%$, and the last class are those over 60 years with a percentage of $2.6 \%$.

The table also shows the proportion of the study sample according to the academic degree where the degree of lecturer came first with a percentage of $33.3 \%$, then a demonstrator with $24.5 \%$, followed by the assistant professor with a percentage of $20.3 \%$, then an assistant lectuerer with a percentage of $19.8 \%$ and in the last rank of them is the professor with a percentage of $2.1 \%$.

\section{Second: Skills of Using the Inernet:}

Table (5)

Internet Skills

\begin{tabular}{|c||c||c||c||}
\hline$\%$ & $\mathrm{H}$ & Use of the Internet & \\
\hline \hline 91.1 & 175 & Yes & 1 \\
\hline \hline 8.9 & 17 & No & $r$ \\
\hline \hline 100 & 192 & Total & \\
\hline
\end{tabular}

Table (5) shows the results of the use of the skills of the participants in the study, where a question is directed about the participants' skills in using the interent, the results were positive as showed by the percentage of participants which reached $91 . \%$. 


\section{Table (6)}

Skills of Using the Inernet

\begin{tabular}{|c||c||c|c|}
\hline$\%$ & $\mathrm{H}$ & Skills of Using the Inernet & \\
\hline \hline 81.7 & 143 & High & 1 \\
\hline \hline 13.7 & 24 & Average & $r$ \\
\hline \hline 4.6 & 8 & Weak & $r$ \\
\hline \hline 100 & 175 & Total & \\
\hline
\end{tabular}

Table number (6) measures the degree of the skill in using the internet by the sample of the study; the highest degree is found among the members of the first rank in the use of the internet with a percentage of $81.7 \%$, followed by the average degree with a percentage of $13.7 \%$, followed by the weak degree with a percentage of $4.6 \%$.

\section{Table (7)}

Time Spent in the Use of the Internet

\begin{tabular}{|c||c||c|c||}
\hline$\%$ & $\mathrm{H}$ & Time Spent in the Use of the Internet & \\
\hline \hline 73.1 & 128 & Numberof hoursper day & N \\
\hline \hline 20.6 & 36 & Numberofhours per week & $r$ \\
\hline \hline 6.3 & 11 & Numberofhours per month & $r$ \\
\hline \hline 100 & 175 & Total & \\
\hline
\end{tabular}

Table (7) shows the time spent in using the internet by the members of the study sample, the highest percentage in the use of the internet a number of hours per day reached $73.1 \%$ of 128 users, with a great difference from the following percentage, a number of hours per day of 36 participants, and a percentage of $20.6 \%$, the result also shows the lower percentage of a number of internet users a number of hours per month, of 11 users and a percentage of $6.3 \%$. 


\section{Third: Vision about Web 2.0}

\section{Table (8)}

The Extent of the Awareness of the Members of the Study Sample of the Information about Web 2.0

\begin{tabular}{|c|c|c|c||}
\hline$\%$ & $\mathrm{H}$ & $\begin{array}{c}\text { The Extent of the Awareness of the Members of the } \\
\text { Study Sample of the Information about Web 2.0 }\end{array}$ & \\
\hline \hline 4.6 & 8 & High & 1 \\
\hline \hline 14.3 & 25 & Average & Weak \\
\hline \hline 81.1 & 142 & Total & \\
\hline \hline 100 & 175 & a & \\
\hline
\end{tabular}

Table (8) indicates the percentage and size of the awareness of the community of the study sample about the Web 2.0, where it turns out that the highest percentage of the study sample have weak information about the Web 2.0; their number is 142 membes, of a percentage of $81.1 \%$ of the participants, with a difference of obviously distant from the percentage with high level of information about the Web, and numbers about 8 participants of a percentage of $4.6 \%$.

\section{Table (9)}

Training on the Use of the Applications of Web 2.0

\begin{tabular}{|c|c||c|c||}
\hline$\%$ & $\mathrm{H}$ & Training on the Use of the Applications of Web 2.0 & \\
\hline \hline 4.6 & 8 & Yes & 1 \\
\hline \hline 95.4 & $17 \mathrm{~V}$ & No & Total \\
\hline \hline 100 & 175 & Tota & \\
\hline
\end{tabular}

Through table number (9) the percentage of trainees on the techniques of Web 2.0 is determined; where the findings revealed that the higher percentage is among those who did not receive training on the Web 2.0, with a percentage of $95.4 \%$, and this percentage indicates a foggy image about the extent of the awareness and information of the Faculty members and their assistants in Beni-Seuf University of the developments and techniques taking 
place in the recent years. Here, great effort is needed to try to overcome this phenomenon.

\section{Table (10)}

Ways of Training on the Use of the Applications of Web 2.0

\begin{tabular}{|c||c|c||c|}
\hline$\%$ & $\mathrm{H}$ & $\begin{array}{c}\text { Ways of Training on the Use of the } \\
\text { Applications of Web 2.0 }\end{array}$ & \\
\hline \hline 22.2 & 4 & Via a Conference or a Seminar & 1 \\
\hline \hline 16.7 & 3 & Via a Training Course & 2 \\
\hline \hline 16.7 & 3 & Via a Workshop & 3 \\
\hline \hline 11.1 & 2 & Via Practical Reading about it & 4 \\
\hline \hline 22.2 & 4 & Via one of the Professors & 5 \\
\hline \hline 11.1 & 2 & Via one of the Colleagues & 6 \\
\hline \hline 100 & 18 & Total & \\
\hline
\end{tabular}

Table (10) shows the ways and means of those who received training on the use of the applications of Web 2.0, the first way, as the results showed, was through a conference or a seminar, and through one of the professors with a number of participants that reached 4 participants, and a percentage of $22.2 \%$ for each. Then through a training course, or attending a workshop with a percentage that reached $16.7 \%$, of 3 participants for each. The third way was through one of the colleagues, or through an academic reading about it, with two participants for each with a percentage of $11.1 \%$. 
Table (11)

Knowledge and Acquaintance with the Applications of Web 2.0

\begin{tabular}{|c|c|c|c|c|c|}
\hline $\begin{array}{l}\text { Don't } \\
\text { know }\end{array}$ & Accepted & Good & $\begin{array}{l}\text { Very } \\
\text { Good }\end{array}$ & Excellent & Applications of Web 2.0 \\
\hline 154 & $\overline{6}$ & 15 & - & - & Folksonomie \\
\hline 158 & - & 17 & - & - & Tags \\
\hline 151 & - & 5 & - & - & Mashup \\
\hline 117 & - & 36 & 11 & - & Wiki \\
\hline 59 & - & 14 & 97 & - & Podcasting \\
\hline- & 13 & 21 & 43 & 9 & Blog \\
\hline 46 & 63 & 35 & 21 & - & RSS \\
\hline 115 & 24 & 17 & - & - & Atom \\
\hline$\overline{6}$ & $\overline{6} 6$ & 34 & - & 126 & $\begin{array}{c}\text { SOCIAL } \\
\text { BOOKMARKING }\end{array}$ \\
\hline
\end{tabular}

The previous table illustrates the extent of the knowledge and acquaintance of the community of the study with the techniques of Web 2.0; each technique is reviewed sperately in order to identify the extent of knowledge and familiarity of the subject of the study, the Faculty members and assistants in Beni-Suef Univeristy, in order to draw a clear picture.

For the Folksonomietechnique "a system of collaborative decentralized spontaneous classification", it does not depend on standard terms, but rather on the terms selected and used by the users themselves. The percentage of those well acquainted with this technique is $8.6 \%$, and with an acceptable degree of $3.4 \%$, whereas the percentage of those who do not have this familiarity with this technique reached to $88.0 \%$.

By "Tags" we mean a sign used by the users to put on the digital text, it can be seen as being key words added by the users to the sites registered in My Web 2.0, and it can even help in organizing the registered pages. The proportion of those well familiar reached $9.7 \%$, while the percentage of those who were not well familiar or well acquainted with this technique reached $90.3 \%$. 
As for the Mashup technique, it is a "compound" technique, a mixture of several resources with the purpose of providing a new service, the percentage of those who were well acquainted with this application reached $5.9 \%$, while the percentage of those who do not have knowledge or familiarity with this application reached to $86.3 \%$, but the degree of knowledge of the remaining percentage has not been specified.

Wiki, is a dynamic Web site, through which the users can adjust the pages they have access to add value. The origin of the term is the language of the people of Hawaii, wikiwiki means "quickly". The percentage of those very well familiar with this application reached $6.3 \%$, the percentage of familiar with it in a good level reached $20.6 \%$, while the percentage of those well familiar with this technique reached to $20.6 \%$, while the percentage of those who do not have familiarity with this application reached to $66.9 \%$, the extent of familiarity with this application by the remaining ratio has not been specified.

As for the technique of "Podcasting", it is a term derived from collecting or composing "iPod" on one hand, and "broadcasting" on the other. It refers to the availability of on-line audio file in a digital format. This file can be directly loaded on the computer. The percentage of those who are "very well" familiar with this application reached 55.4\%, and that of those with "good" familiarity with the technique $8.0 \%$, while that of those who do not have knowledge of the this application is $78.7 \%$, the extent of the knowledge of the remaining percentage has not been specified yet.

"Blog": a web site, any web page or web site is characterized by continuous publishing, and is updated on a continuous basis, it includes entries or notations, dated and arranged in a chronological basis beginning with the the most recent. The percentage of those with 'excellent' knowledge of this application reached to $52.0 \%$, and those with 'very good' knowledge of it reached to $24.6 \%$, and that of those with 'accepted' knowledge of the application reached $7.4 \%$, while the extent of the knowledge of the remaining percentage has not been specified yet. 
"RSS" is an abbreviation of "Really Simple Syndication" or "Rich Site Summary", which means the summaries of Web sites; it allows extracting the content related to a Web site on a regular and automatically updated basis. RSS file is considered a text file, according to an XML format that includes description of general compositions of the content. The percentage of those with 'very good' knowledge of this application reached to $12.0 \%$, and those with 'good' knowledge of this application reached to $20.0 \%$, and that of those with 'accepted' knowledge of the application reached $36.0 \%$, while that of those who do not have knowledge of it reached $26.3 \%$, but the extent of the knowledge of the remaining percentage has not been specified yet.

"Atom": provides licenses for the content of various sources of the Web, a "competitor to serve RSS". The percentage of those with 'good' knowledge of this application reached to $9.7 \%$, and those with 'accepted' knowledge of it reached to $13.7 \%$, while that of those who do not have knowledge of it reached $65.7 \%$, but the extent of the knowledge of the remaining percentage has not been specified yet.

Finally, there is the technique of "SOCIAL BOOKMAKRING", which means social networks, the purpose of which is to activate the software teckniques, and hardware technology, and networks to provide an interactive electronic participatory diaglogic democratic environment as desired by its founders. The percentage of those with 'excellent' knowledge of this application reached to $72.5 \%$, and those with 'good' knowledge of it reached to $19.4 \%$, while that of those who have 'accepted' knowledge of it along with those who do not have knowledge of it reached $4.4 \%$, while knowledge of the remaining percentage has not been specified yet.

Through the previous revision of the extent of the familiarity of the community of the study with the applications of Web 2.0, we find an obvious disparity in the degree of knowledge of these applications, we observe that the decrease with respected to each tecknique of Folksonomie, Tags, and Mashup, while we find a slight increase in the rates of knowledge 
and familiarity with all of the technical Wiki, and the techniques of RSS, and Atom.

The luckiest technique is "Podcasting", "Blog", and SOCIAL BOOKMARKING; the reason for this is the proliferation of these technologies at the level of broad online.

Because the goal of this study is to investigate the use of the Faculty members and assistants in Beni-Suef University of Web 2.0, it is natural to identify the rate of using the services and available sites, that depends on the techniques of Web 2.0, where the the study identified the most prevalent services and sites, they are found as the following table demonstrates:

\section{Table (12)}

The Rate of the Use of Services and Available Sites

Based on Techniques of Web 2.0

\begin{tabular}{|c|c|c|c|c|c|}
\hline 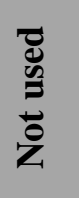 & 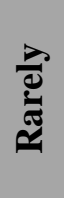 & 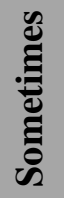 & 巳ँ & 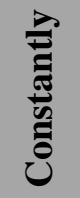 & \\
\hline & & & & 168 & $\begin{array}{c}\text { Youtube } \\
\begin{array}{c}\text { Application Platformof Video FilesMade Available } \\
\text { bythe Participants }\end{array}\end{array}$ \\
\hline & & 95 & & & $\begin{array}{l}\text { Flickr } \\
\text { Supports Participation in PicturesDirectly on - line }\end{array}$ \\
\hline 154 & & & & & $\begin{array}{c}\text { BitTorrent: } \\
\text { File Sharing Program According to Point to Point } \\
(\text { p2p })\end{array}$ \\
\hline & & 79 & & & $\begin{array}{c}\text { MySpace: } \\
\text { Social Networkthat AllowsMembersto Compilethe } \\
\text { Participants in theSame Concerns }\end{array}$ \\
\hline & & & & 169 & $\begin{array}{c}\text { Facebook: } \\
\text { Social Networkthat AllowsMembersto Compilethe } \\
\text { Participants in theSame Concerns }\end{array}$ \\
\hline 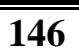 & & & & & 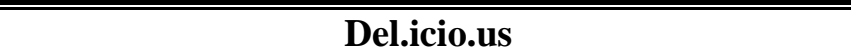 \\
\hline
\end{tabular}


Maha Ahmad Ibrahim Mohammad. (BIJHS) 2019, 1 (1): 213 -248

\begin{tabular}{|c|c|c|c|c|}
\hline & & & & Network that Aims at Social Bookmarking \\
\hline & & & 137 & $\begin{array}{c}\text { Wikipedia: } \\
\text { Co-operative Encyclopedia }\end{array}$ \\
\hline & 123 & & & $\begin{array}{c}\text { Wikimedia: } \\
\text { An Auditory Visual Library }\end{array}$ \\
\hline & 123 & & & $\begin{array}{c}\text { WIKIBOX } \\
\text { A Digital Library }\end{array}$ \\
\hline 146 & & & & $\begin{array}{c}\text { Yoono: } \\
\text { A Collaborative Search Engine, a Search Engine in } \\
\text { the Sites that Follows Classification with Key } \\
\text { Wrods }\end{array}$ \\
\hline & & 97 & & $\begin{array}{c}\text { Technorati } \\
\text { A search enginefor blogs, } \\
\text { searchthroughtheavailablefull text, or Through } \\
\text { (Key Words, Descriptive)Tags, Doing } \\
\text { Informational Research on Blogs Accroding to } \\
\text { Keywords }\end{array}$ \\
\hline 123 & & & & $\begin{array}{l}\text { Netvibes: } \\
\text { CustomizableHomepage(Organizing Information } \\
\text { According toUserinterests), Which Allows for the } \\
\text { Collectionof PersonalEmail Addresses, RSS etc. }\end{array}$ \\
\hline 146 & & & & $\begin{array}{c}\text { Writely Internet Services, } \\
\text { aWord Processorto Editand WriteDocuments, } \\
\text { Found in theWebandWhenyou FinishWritingYour } \\
\text { Documentis Savedinthe Services of } \\
\text { WritelyInternet, so as tobe Able toReach themon } \\
\text { any Devicein anywhereof the World }\end{array}$ \\
\hline$\overline{146}$ & & & & $\begin{array}{c}\text { Zimbra } \\
\text { Email }\end{array}$ \\
\hline & & & 163 & $\begin{array}{l}\text { Gmail } \\
\text { Email }\end{array}$ \\
\hline 146 & & & & $\begin{array}{c}\text { iTune Program } \\
\text { Programto OrganizeAudio FilesandShare Themor } \\
\text { Postedon the Web }\end{array}$ \\
\hline$\overline{146}$ & & & & $\begin{array}{c}\text { Services of Rearden Company: } \\
\text { A Private Web Trip Services }\end{array}$ \\
\hline
\end{tabular}


BSU International Journal of Humanities and social science

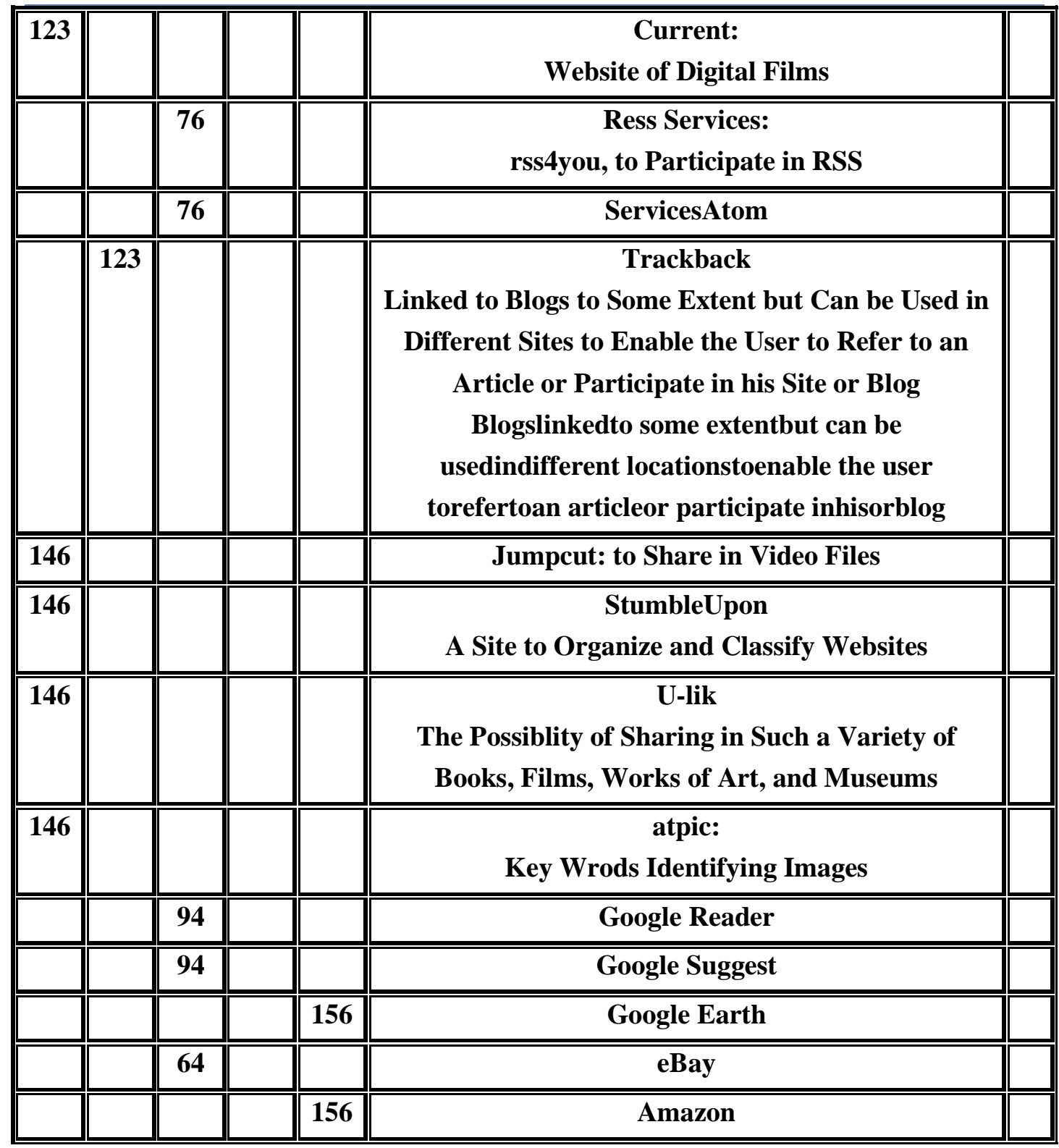

We find that the Facebook site, a social network that allows collecting members involved in the same concerns, occupies the first place in the permanent Utilization rate, reaching $96.6 \%$ by 169 members, followed by the Youtube site, an application platform for video files available by the participants with a percentage of $96 \%$, followed by the Gmail with a percentage of $93.1 \%$, with 163 members, and even the percentage of both Google Earth, and Amzon, where 156 members with a percentage of 89.1\% for each, finally Wikipedia site, a collaborative Encycolpedia, with 78.3\%. 
Let's move to the utilization rate, where Blogs search engine Technorati which often occupies the first rank; where it carries out an information research on blogs in accordance with the keywords provided; because the research is available in it through the full text, or through tags (Key words, Descriptions), where 97 members registered with a percentage of 55. 4\%, followed by the percentage of Flickr site which supports participation in the pictures on the direct line of $54.3 \%$. The percentage of both Google Reader, Google Suggest, as reported by 94 members using almost intermittently, hit 53.7 for each. Then MySpace site, a social network that allows compiling members participants in the same concerns, hits 45.3\%. The percentage the services of both RSS and Atom, reached $43.4 \%$ for each, whereas eBay site recorded the lowest percentage of sites and services that are mostly used by the community of the study, which recorded a percentage of $36.6 \%$.

As for the Faculty members and teaching assistants in Beni-Suef University who reported the scarcity of their use of the available services and sites based on the techniques of Web 2.0, it is found that the percentage of their use of these techniques reached $70.3 \%$ of both Trackback related to blogs, but can be used in different sites to enable users to refer to an article, or participate in his site or blog, and the Wikimedia site which is an audiovisual library, and WIKIBOX which is a digital library.

Moving to the services and sites available on Web 2.0, which the community of the study reported not using, BitTorrent comes in the forefront, it is a file-sharing program in accordance with Point to Point (P2P) with a percentage of $88 \%$, followed by a percentage of $83.4 \%$ who reported not using these following nine sites and services, Yoono: a collaborative search engine about the sites affiliated to classification by keywords, the internet Writerly: a word processor to write and edit documents, found on the web, when you finish writing your document it saves it in the services of Internet Writerly, so that you have the ability to reach it via any device and anywhere in the world. We have also Del.icio.us site, a network targeted to participate in the favorites Social Bookmarking program, and iTune program 
to organize audio files, and share in publishing in the web, and email Zimbra, and the site Jumpcut to share in video files, and StumbleUpon site to organize and classify webpages, and $\boldsymbol{U}$-like site to enable particpation in a variety of books, films and works of art, museums, and then atpic to determine keywords on images.

Netvibes site, a customizable homepage (organization of information according to user interests), which allows collecting personal email addresses, RSS, and so on. CURRENT website for digital films, recorded a percentage of $70.3 \%$, by 123 members.

From the above it is noticed that the high rate of available services and sites based on the techniques of Web 2.0, which have never been used by members of the Faculty and teaching assistants in Beni-Suef University, the subject of the study, which reached $43.3 \%$ by 13 sites out of 30 , the total number of sites and services, as illustrated in the following table:

\section{Table (13)}

Rate of Use of Available Services and Sites

Based on the Techniques of the Web 2.0

\begin{tabular}{|c|c|c|}
\hline$\%$ & Number & Utilization rate \\
\hline 20 & 6 & Always \\
\hline- & - & Often \\
\hline 26.7 & 8 & Sometimes \\
\hline 10 & 3 & Scarcely \\
\hline 43.3 & 13 & Non-use \\
\hline 100 & 30 & Total \\
\hline
\end{tabular}

The above table shows the lack of awareness of the Faculty members and the teaching assistants in Beni-Suef University, their obvious lack of knowledge of Web 2.0, which is evident from their non-use and non-benefit from the services and sites available approved applications of Web 2.0, which urgently requires us to attempt knowing their views about available services and sites based on the techniques on Web 2.0, through the following table: 


\section{Table (14)}

The studyonthe views ofcommunityservices andsites availableandapprovedtechniques

Views of the Study Community about the Availabe and Approved Services and Sites on the Applications of Web 2.0

\begin{tabular}{|c|c|c|c|c|c|c|}
\hline$\overline{\%}$ & 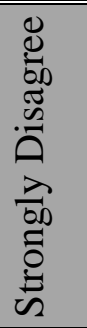 & 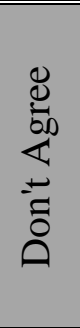 & 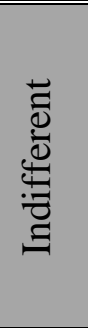 & 总 & 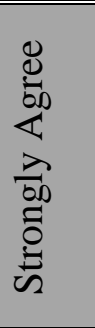 & \\
\hline 89.1 & & & 156 & & & $\begin{array}{l}\text { The existence ofwhat meetsmy } \\
\text { informatic needs }\end{array}$ \\
\hline 85.1 & 149 & & & & & Trustin the availableinformation in it \\
\hline 81.7 & & 143 & & & & $\begin{array}{l}\text { The stability ofthe content andits } \\
\text { continued existence }\end{array}$ \\
\hline 94.3 & & & & & 165 & The need to useWeb services \\
\hline 94.3 & & & & & 165 & Encourage Using Web Services \\
\hline 78.3 & & & 137 & & & $\begin{array}{l}\text { Authenticity and Accuracy of } \\
\text { Inforation }\end{array}$ \\
\hline 94.3 & & & & & 165 & $\begin{array}{l}\text { Knowing the Most Up - to date } \\
\text { Technical Developments }\end{array}$ \\
\hline 73.7 & & & 129 & & & $\begin{array}{c}\text { Easy Handling, Searching and } \\
\text { Retrieval }\end{array}$ \\
\hline 73.7 & & & 129 & & & Possibility of Laoding and Printing \\
\hline 85.1 & & & & 149 & & Fast Access to Information \\
\hline 81.7 & & & & & 143 & $\begin{array}{c}\text { No-Compliance with the Factors of } \\
\text { Time and Place }\end{array}$ \\
\hline
\end{tabular}

The above table shows the willingness of the Faculty members and teaching assistants in Beni-Suef University to use, and benefit from the techniques of Web2.0, where 165 members agreed strongly on the need for the use of web services, encourage using it, and knowing about the latest technical developments, at a rate of $94.3 \%$ for each, while we find the 
percentage of those who said that they had fast access to the information reached to $85.1 \%$.

This is followed by those who neutrally see that the available services and sites based on the techniques of Web 2.0, and those who see that they meet the informatic needs, a percentage of $89.1 \%$, then who see the authenticity and accuracy of information with the percentage of $78.3 \%$, also the percentage of those who neutrally see the easiness of dealing, searching, retrieving, and possibility of loading, and printing of data, is $73.7 \%$ for each. About 143 members reported about their disagreement on the stability of the content, and the continuity of its existence with a percentage of $81.7 \%$, also a percentage of $85.1 \%$ reported of their strong disagreement of the degree of authenticity of the available information.

\section{Results and Recommendations}

\section{Results:}

1- A high percentage of those who possess high skills in the use of the internet is noticed, with a percentage of $81.7 \%$.

2- The information of a higher percentage of study samples is weak, their number reached 142 with a percentage of $81.1 \%$ of the participants, and a clear difference from the percentage of those whose information about the web is high, and their number is 8 participants with a percentage of $4.6 \%$.

3- The highest percentage of those who did not get any training on the use of the techniques of Web 2.0 is $95.4 \%$, the remaining percentage is $4.6 \%$ who received training on the use of the applications of Web 2.0, the first way, as the results show, was through a conference or a seminar, then through a training course, or through attending a workshop, the third way is through a colleague, or through academic reading about it, with a number of two participants for each with a percentage of $11.1 \%$.

4- There is a sharp decrease in both the techniques of Folksonomie, Tags, and Mashup, while there is a bit of increase in the rates of knowledge and acquaintance with the tecknquies of Wiki, RSS, and Atom, and the less 
fortunate techniques: Podcasting, Blog, and Social Bookmarking, the reason for this may be the proliferation of these technologies broadly on the internet.

5- Facebook site which occupies the first rank in the rate of use on permament basis, reaching a percentage of $96.6 \%$, then the Youtube site by 96\%, followed by Gmail with a percentage of 93.1\%, Google Earth, Amazon are used equally with a percentage of $89.1 \%$ each, finally Wikipedia is reported to be used with a percentage of $78.3 \%$.

6- The blogs search engine Technorati occupies the first rank where 97 members are registered with a percentage of 55.4\%, followed by $\boldsymbol{F l i c k r}$ with a percentage of 54.3\%, while the percentages of Google Reader, Google Suggest, and Myspace are equal. Also the percentages of both RSS and Atom are equal too, whereas $\boldsymbol{e B a y}$ site recorded the lowest percentage of the sites and services used by the members of the community of the study, mostly recorded a rate of $36.6 \%$.

7- Scarcity of use of available services and sites based on the techniques of Web 2.0, with a percentage of 70.3\%, in Trackback related to some extent - to Blogs.

8- Members of the community of the study reported their non-use of the BitTorrent, a program which exchange files in accordance to Point to Point $(P 2 p)$ with a percentage of $88 \%$, followed by the collaborative search engine Yoono, and services of Internet Writerly, then the site Del.icio.us, and Zimbra email, Jumpcut site, StumbleUpon site, U-likesite, and atpic site.

9- Netvibes, a site that allows collecting all personal email addresses, $\boldsymbol{R S S}$ and so on, and the Current site for digital films, with a percentage of $70.3 \%$.

10- An increase in the rates of available services and sites based on the techniques of Web 2.0, which the members of the Faculty and teaching assistants in Beni-Suef University never used, with a percentage of $43.3 \%$. 
11- Lack of awareness and acquaintance of the Faculty and teaching assistants in Beni-Suef University, with the techniques of Web 2.0, which is clearer in their non-use and non-benefiting from the available services and sites based on the techniques of Web 2.0.

12- The willingness of the Faculty and teaching assistants at Beni-Suef University, to use and benefit from the techniques of Web 2.0, with a percentage of $94.3 \%$ for each.

\section{Recommendations:}

1- Working to raise the awareness of the Faculty and teaching assistants in Beni-Suef University in using the techniques of the Web 2.0.

2- Holding seminars and workshops to introduce the techniques and latest developments in the field.

4- Revisiting the training competences provided by the Center of Developing the Skills of the University Faculty Members, with the view to add a training competence related to training on the most up-to date techniques, the following examples:

a- a training course on Web techniques

b- a training course on Nano-Technology

c- a training course on biometrics

d- a training coruse on Second Life... etc. 


\section{References}

( ${ }^{1}$ ) Constantinides ,Efthymios \& Fountain ,Stefan J 8. Web 2.0: Conceptual foundations and marketing issues . - Journal of Direct, Data and Digital Marketing Practice (2008) 9, 231-244

( ) Boulos' Maged N. Kamel\& Wheeler, Steve. The emerging Web 2.0 social software: an enabling suite of sociable technologies in health and health care education.- Health Information \& Libraries Journal- Volume 24, Issue 1, pages 2-23, March 2007

) 3(Maness, J. (2006). "Library 2.0 Theory: Web 2.0 and Its Implications for Libraries". Webology, 3 (2), Article 25. Available at: http://www.webology.org/2006/v3n2/a25.html

${ }^{4}$ ) BALCIKANLI,Cem.LANGUAGE LEARNING IN SECOND LIFE: American and Turkish Students' Experiences. Turkish Online Journal of Distance Education-TOJDE .- Volume: 13 Number: 2 Article 5.- (April 2012)

( ${ }^{5}$ Tosic, M.\& Manic, M. A RESTful technique for collaborative learning content transclusion by Wiki-style mashups.- e-Learning in Industrial Electronics (ICELIE), 2011 5th IEEE International Conference on 7-10 Nov. 2011 Pages $38-43$

( ${ }^{6}$ )Selwyn , Neil . Web 2.0 applications as alternative environments for informal learning - a critical review. paper for OECD-KERIS expert meeting - Session 6 - Alternative learning environments in

practice: using ICT to change impact and outcomes.

${ }^{7}$ ) Wheeler, Steven\&Boulos, MagedKamel. Mashing, burning, mixing and the destructive creativity of Web 2.0: applications for medical education . - RECIIS - Electronic Journal of Communication,

Information \& Innovation in Health, v.1, n.1, p.27-33, Jan.-Jun., 2007

( ${ }^{8}$ )SayyedHassaballah, M. Galal el-Ghandour, Statistics for Librarians, Riyadh, Mars Publishing Agency.

* Numbers of the Faculty members and their assistants during the year 2011/2012 (Beni-Suef University Administration, March 2012)

( ${ }^{9}$ Al-Khalifa, Hind BintSouliman (2006), Employment of the Techniques of Web 2.0 in the Service of E-Learning, The Fourth Technical Saudi Conference for Technical and Professional Training, Riydadh, Saudi Arabia.

$\left({ }^{10}\right)$ http://www.webopedia.com/TERM/W/Web_2_point_0.html

(11) O'Reilly, Tim. What is Web 2.0: Design Patterns and Business Models for the Next Generation of Software.Communications \& Strategies, No. 1, p. 17, First Quarter 2007 Available at

http://papers.ssrn.com/sol3/papers.cfm?abstract id=1008839

$\left({ }^{12}\right.$ ) San, Murugesan .Understanding Web 2.0 .- IT Professional (Volume:9 , Issue: 4 ) July-Aug. 2007 Page(s):34 - 41 Available athttp://ieeexplore.ieee.org/xpl/login.jsp?tp=\&arnumber=4287373\&url=http\%3A\%2F\%2Fieexplore.ieee.org\%2Fxpls\%2Fa bs_all.jsp\%3Farnumber\%3D4287373

$\left({ }^{13}\right)$ Ibid 